\title{
Pilot Study: The Training of Health Professionals about Geneticalle Modified Foods from the Perspective of the Science, Technology and Society
}

\author{
Isabella R F Vieira ${ }^{1 *}$, Teresa RS Brandão ${ }^{1}$, Elisabete Pinto ${ }^{1,2}$ and Margarida Silva ${ }^{1}$ \\ ${ }^{1}$ University of Católica Portuguese, CBQF - Center for Biotechnology and Fine Chemistry, Associated Laboratory, School of \\ Biotechnology, Portugal
}

${ }^{2}$ EPIUnit - Institute of Public Health, University of Porto, Portugal

*Corresponding author: Isabella RF Vieira, University of Católica Portuguese, CBQF - Center for Biotechnology and Fine Chemistry, Associated Laboratory, School of Biotechnology, Rua Arquiteto Lobão Vital 172, 4200-374 Porto, Portugal

\section{ARTICLE INFO}

Received: 慧 February 16, 2020

Published: 慧 March 01, 2021

Citation: Isabella R F Vieira, Teresa RS Brandão, Elisabete Pinto, Margarida Silva. Pilot Study: The Training of Health Professionals about Geneticalle Modified Foods from the Perspective of the Science, Technology and Society. Biomed J Sci \& Tech Res 34(2)-2021. BJSTR. MS.ID.005523.

Keywords: Training; Transgenic Foods; Nutritionists; Doctors; Scientific; Technological and Societal

\begin{abstract}
The objective of this work was to establish and assess a training module for Nutrition Sciences and Medical Sciences in relation to transgenic food, and additionally to contribute to the construction of a comprehensive learning concept involving scientific, technological and social knowledge. This module is an integrative and multidisciplinary proposal that studies the transgenic foods currently on the market through an integrated scientific, technological and societal approach. The topics offered in the module were: genetics, health, the environment, legislation, ethics, controversies, concerns, visions of the various stakeholders, the scientific method, uncertainty and the precautionary principle. Was evaluated from September to December 2018 through a questionnaire and interview. Were analyzed in the program SPSS, and the interviews in the program Nvivo using content analysis techniques. Participants include: 7 nutritionists and 7 physicians. The structure of the training module presented is innovative and has its genesis in the current Transgenic food state of art. It has been found that both physicians and nutritionists agree with most of the topics.
\end{abstract}

For both nutritionists and physicians, topics with a greater level of agreement were related to "Health" and the lowest level of agreement regarded "Stakeholders' insight". For the interviewees, the module's contents are well structured, comprehensive, well explained and organized by topic. With unanimity, the individuals involved in this study agree and consider the themes presented in the module structure to be important, although there is a difference between the courses of nutrition science and medicine regarding the way in which training is offered as well as differences in some content.

\section{Introduction}

In the last two decades, the social controversy over the benefits and harms in health and the environment about transgenic food (TF) [1], as well as concerns about the monopoly of world trade, the reliability of public institutions, the integrity of regulatory agencies, the loss of both individual and ethical choice, and the future of food supply, have kept the national and international public discussion alive [2]. It is in this context of technological complexity that the role of health professionals gains an unexpected significance. In spite of officially guaranteeing legal criteria and, until now, despite the fact that negative impacts on health or the environment are controversial
[3], the process of authorization and commercialization of $\mathrm{TF}$ cannot prevent the possibility of unforeseen (by definition) surprises, which puts health professionals at a critical point in providing information and reliably advising patients, answering questions and maximizing safety and wise behaviors.

The TF topic presents several challenges, related to thought fragmentation and to the proliferation of knowledge that quickly changes, dividing itself in isolated areas. In order to understand TF, more integrated analyses are needed, including diverse perspectives and scientific and professional experiences. A new model of 
attention and training concerning TF for health professionals is needed in order to update and broaden these professionals' thought. The objective of this work was to set and assess a training module for Nutrition Sciences and Medical Sciences in relation to TF, in addition to contributing to the construction of a comprehensive learning concept connected to scientific, technological and social knowledge.

\section{Methods}

\section{Creating the Module Structure}

This teaching module (topics included in Table 1) is an integrative and multidisciplinary proposal [5] that focuses on the TF on the market nowadays, through a scientific, technological and societal approach (STS) [2,4]. Transgenic foods were discussed in order to include the perspective of objective information (general topics) [6-10] and the perspective of uncertain information (transversal themes) [11-15].

\section{Evaluation of the Module's Structure}

Instruments: Three instruments were designed to evaluate the module's structure. Instrument 1 consisted of a survey (i) that was created using closed questions with a 5-level Likert scale to assess agreement (1-strongly disagree, 2-disagree, 3- neither disagree nor disagree, 4-agree, 5-strongly agree) and importance (1-unimportant, 2- little important, 3- neither little important nor unimportant, 4-important, 5-very important) with the contents presented in the module. Instrument 2 (ii) consisted of a survey with open questions that were placed in a semi-structured interview to evaluate content, structure, emerging topics, inclusion of the module in the degree's plan, difficulties, and qualifications to be developed within training. The third and final instrument (iii) was a module evaluation survey that, besides being made up of closed questions of agreement and importance (concerning instrument 1 ).

Participants: Participants in this study include: 14 health professionals, of whom 7 were nutritionists and the other 7 physicians, including academic and professional representatives working as nutritionists or physicians. The inclusion criterion for instruments 1 and 2 was to be a professor affiliated with a university. The sample consisted of 5 representatives from medical schools and 5 from faculties with degrees in Nutrition Sciences. For instrument 3 , sampling was carried out in the private sector. Physicians and nutritionists who practiced the profession were contacted. Four professionals ( 2 doctors and 2 nutritionists) participated.

Data collection: Data collection took place from September to December of 2018 through three activities. The objective of each action was previously highlighted, and the confidentiality of the information collected was guaranteed. The first activity consisted in disseminating instrument 1 online. Subsequently, semi-structured interviews were carried out in person at the participants' universities (instrument 2). Training was carried with a duration of 4 hours, focusing on the contents of Table 1. Subsequently, presented as a lecture, the module was evaluated with regard to the agreement and importance of contents and opinions about the knowledge acquired (tool 3).

Data Analysis: The results of the interviews (instrument 2) were analyzed in the program Nvivo ${ }^{\circledR}$ version 11.4 .2 (QSR International, Pty Ltd.) using the techniques of content analysis according to Bardin [16], through three chronological segments: a pre -analysis (organization of research material), material exploration (procedures for coding, classifying and categorizing collected material) results processing, inference and interpretation. Data from surveys (instruments 1 and 3) were exported from Microsoft ${ }^{\circledR}$ Excel $\AA$ (Microsoft Corporation, version 14.5.7) and later analyzed in the IBM SPSS Statistics 23 for Windows $\AA$ program (SPSS Inc., Chicago, USA). Measurements of central tendency (mean) and dispersion (standard deviation) were used to characterize the sample data concerning agreement and importance of the module's contents. Qui-square independence tests were carried out in association with a correspondence analysis to investigate associations between the questions and the sociodemographic characteristics of the respondents. The level of significance assumed was 5\%. The surveys' internal consistency was evaluated based on Cronbach's alpha value. These values range from 0 to 1 , the internal consistency of a survey being greater when the value is closer to 1 [17].

\section{Results}

\section{Participants' Description}

Of the 14 participants, $78 \%$ were women and $22 \%$ were men, all aged between 26 and 69, and living in cities in North and Central Portugal. They work in areas related to clinical nutrition, oncology, anatomy, research methodology, nutrition and life cycle, gastrotechnics, food, food toxicology, family medicine and cardiology. Universities collaborating in this research were: University of Porto, Piaget Institute of Viseu, CESPU, University of Lisbon, University of Trás-os-Montes and Alto do Douro, University of Coimbra, "Nova" University of Lisbon and University of Beira Interior. The duties performed by the 10 participants are: supervisor, headmaster or executive supervisor. The participants are associate or assistant professors. The four participants from the private sector work in the family medicine, nutrition and oncology areas.

\section{Surveys}

The degree of agreement was evaluated in relation to the twelve topics related to TF (Table 1). It has been found that both physicians and nutritionists agree or strongly agree with most of the topics to be included in TF training (mean score for response score greater than 4). Only in item 10, and for both professionals, the average was slightly below a score of 4 . For both nutritionists and physicians, topics with a greater level agreement were related to "Health" and the lowest level of agreement lies in the "Stakeholders' insight". In terms of the topics' relevance, physicians considered all of them 
important or very important. Only the "Controversies" topic had a lower average rating, with a score of 3.8. Nutritionists also classified most of the topics as important or very important, but the topics "Genetics", "Concerns", "Controversies" and "Stakeholders' insight" obtained a lower average score, classified as neither important nor important by this group of health professionals.

For both nutritionists and physicians, "Health" was the topic that had the least variation (assessed by the standard deviation) of answers concerning agreement and importance. The "Precautionary Principle" was the topic that presented less variation in responses of importance for nutritionists. In order to measure the reliability of the surveys' items, the Cronbach Alpha test was applied. The numbers obtained were 0.94 for agreement and 0.97 for significance, revealing high internal consistency. Physicians' and nutritionists' agreement and importance responses were independent ( $p>0.05$ ) of all characterization data (gender, age, place of work and / or profession) (Table 1).

Table 1: Classification of agreement and importance attributed by nutritionists and physicians to the contents of the training module.

\begin{tabular}{|c|c|c|c|c|c|c|c|c|}
\hline \multirow{3}{*}{$\begin{array}{c}\text { Contents of the training module } \\
\text { General Topics }\end{array}$} & \multicolumn{4}{|c|}{ Agreement } & \multicolumn{4}{|c|}{ Importance } \\
\hline & \multicolumn{2}{|c|}{ Nutritionists } & \multicolumn{2}{|c|}{ Physicians } & \multicolumn{2}{|c|}{ Nutritionists } & \multicolumn{2}{|c|}{ Physicians } \\
\hline & $\mathbf{x}$ & $\mathbf{s}$ & $\mathbf{x}$ & $\mathbf{s}$ & $\mathbf{x}$ & $\mathbf{s}$ & $\mathbf{x}$ & $\mathbf{s}$ \\
\hline \multirow{4}{*}{$\begin{array}{l}\text { 1. Genetics } \\
1.1 \text { TF definition. } \\
1.2 \text { Current and new techniques of genetic modification (method, process } \\
\text { and results). } \\
\text { 1.3 Modified characteristics (in use, under study and future ones). }\end{array}$} & 4,4 & 0,5 & 4,3 & 0,9 & 3,9 & 0,7 & 4,0 & 1,2 \\
\hline & 4,6 & 0,5 & 4,6 & 0,5 & 4,1 & 0,9 & 4,1 & 1,2 \\
\hline & 4,1 & 0,4 & 4,1 & 1,2 & 3,6 & 0,8 & 4,0 & 1,2 \\
\hline & 4,4 & 0,5 & 4,1 & 1,1 & 3,9 & 0,4 & 3,9 & 1,3 \\
\hline \multirow{2}{*}{$\begin{array}{l}\text { 2. Nutrition } \\
2.1 \text { Purpose and challenges of the production of transgenic foods sold in } \\
\text { Portugal and the EU. }\end{array}$} & 4,7 & 0,5 & 4,4 & 0,8 & 4,6 & 0,8 & 4,3 & 1,5 \\
\hline & 4,7 & 0,5 & 4,4 & 0,8 & 4,6 & 0,8 & 4,3 & 1,5 \\
\hline \multirow{8}{*}{$\begin{array}{l}\text { 3. Health } \\
3.1 \text { Health consequences. } \\
\text { 4. Environment } \\
4.1 \text { Interaction of genetically modified crops with the environment. } \\
\text { 5. Ethics } \\
5.1 \text { Ethical principles implied by transgenic food technology. } \\
\text { 6. Legislation } \\
\text { 6.1Safety assessment of transgenic foods. }\end{array}$} & 5,0 & 0,0 & 4,7 & 0,5 & 4,7 & 0,5 & 4,9 & 0,4 \\
\hline & 5,0 & 0,0 & 4,7 & 0,5 & 4,7 & 0,5 & 4,9 & 0,4 \\
\hline & 4,6 & 0,5 & 4,6 & 0,8 & 4,0 & 1,0 & 4,3 & 1,0 \\
\hline & 4,6 & 0,5 & 4,6 & 0,8 & 4,0 & 1,0 & 4,3 & 1,0 \\
\hline & 4,4 & 0,5 & 4,4 & 1,1 & 4,0 & 1,0 & 4,3 & 1,1 \\
\hline & 4,4 & 0,5 & 4,4 & 1,1 & 4,0 & 1,0 & 4,3 & 1,1 \\
\hline & 4,7 & 0,5 & 4,3 & 1,0 & 4,3 & 1,3 & 4,1 & 0,9 \\
\hline & 4,7 & 0,5 & 4,3 & 1,0 & 4,3 & 1,3 & 4,1 & 0,9 \\
\hline \multicolumn{9}{|l|}{ Transversal Topics } \\
\hline \multirow{8}{*}{$\begin{array}{l}\text { 7. Concerns } \\
\text { 7.1 Concerns about genetic engineering methodologies. } 7.2 \text { Concerns about } \\
\text { interactions with health. }\end{array}$} & 4,2 & 0,5 & 4,1 & 1,2 & 3,7 & 0,9 & 4,0 & 1,0 \\
\hline & 4,0 & 0,6 & 3,9 & 1,2 & 3,6 & 0,5 & 4,0 & 1,0 \\
\hline & 5,0 & 0,0 & 4,4 & 1,1 & 4,6 & 0,5 & 4,3 & 1,0 \\
\hline & 4,7 & 0,5 & 4,4 & 1,1 & 4,3 & 1,0 & 4,1 & 0,9 \\
\hline & 4,0 & 0,6 & 4,0 & 1,3 & 3,3 & 1,1 & 4,0 & 1,0 \\
\hline & 3,4 & 0,5 & 4,1 & 1,2 & 3,0 & 1,0 & 3,7 & 1,0 \\
\hline & 4,0 & 0,6 & 4,3 & 1,3 & 3,6 & 1,0 & 3,9 & 0,9 \\
\hline & 4,0 & 0,8 & 3,9 & 1,2 & 3,6 & 1,0 & 3,9 & 1,1 \\
\hline \multirow{4}{*}{$\begin{array}{l}\text { 8. Controversies } \\
8.1 \text { Controversy regarding the effects of the consumption of transgenic } \\
\text { foods on health. } \\
8.2 \text { Controversy regarding the findings of the use of genetic engineering. } \\
8.3 \text { Controversy regarding GM food approval procedures. }\end{array}$} & 4,1 & 0,5 & 4,0 & 1,2 & 3,9 & 0,8 & 3,8 & 1,2 \\
\hline & 4,7 & 0,5 & 4,1 & 1,2 & 4,6 & 0,8 & 4,0 & 1,3 \\
\hline & 3,7 & 0,5 & 3,7 & 1,3 & 3,6 & 0,5 & 3,6 & 1,1 \\
\hline & 4,0 & 0,6 & 4,1 & 1,2 & 3,6 & 1,0 & 3,7 & 1,1 \\
\hline \multirow{4}{*}{$\begin{array}{l}\text { 9. Scientific Method } \\
\text { 9.1 Science and values. } \\
\text { 9.2 Limits: on knowledge concerning genetics, consumption, approval laws, } \\
\text { effects on the environment, and unintended effects - unknown to science. } \\
\text { 9.3 Types of uncertainties - quantitative and qualitative. }\end{array}$} & 4,2 & 0,6 & 4,1 & 1,2 & 3,9 & 0,8 & 4,0 & 1,0 \\
\hline & 4,0 & 0,8 & 4,3 & 1,0 & 3,4 & 0,8 & 4,1 & 1,1 \\
\hline & 4,6 & 0,5 & 4,3 & 1,0 & 4,3 & 0,8 & 4,0 & 1,0 \\
\hline & 4,1 & 0,4 & 3,9 & 1,6 & 3,9 & 0,9 & 3,9 & 0,9 \\
\hline
\end{tabular}




\begin{tabular}{|c|c|c|c|c|c|c|c|c|}
\hline 10. Stakeholders's insights & 3,9 & 0,7 & 3,8 & 1,6 & 3,4 & 0,9 & 4,0 & 1,2 \\
\hline \multirow{2}{*}{$\begin{array}{l}10.1 \text { Concept and structure of the food system. 10.2Perspective of } \\
\text { agrobiotechnological companies. }\end{array}$} & 4,1 & 0,7 & 3,7 & 1,6 & 3,4 & 0,5 & 4,1 & 1,2 \\
\hline & 3,9 & 0,7 & 3,7 & 1,6 & 3,0 & 0,8 & 3,9 & 1,2 \\
\hline 10.3 Scientists' point of view & 3,6 & 1,0 & 3,9 & 1,7 & 3,3 & 1,0 & 4,0 & 1,2 \\
\hline 10.4 Aspects of interpretation of non-governmental organizations. & 3,7 & 0,5 & 3,7 & 1,6 & 3,1 & 0,9 & 3,9 & 1,2 \\
\hline 10.5 Overview of family farmers. & 4,1 & 0,7 & 3,9 & 1,7 & 3,7 & 1,1 & 4,0 & 1,2 \\
\hline 10.6 Consumers' perceptions. & 4,6 & 0,5 & 3,9 & 1,7 & 3,7 & 1,1 & 4,1 & 1,2 \\
\hline 10.7 Scenario through the politicians' perspective. & 3,4 & 0,5 & 3,7 & 1,6 & 3,1 & 0,7 & 3,9 & 1,2 \\
\hline 11. Precautionary principle & 4,9 & 0,4 & 4,6 & 0,8 & 4,4 & 0,5 & 4,3 & 1,0 \\
\hline 11.1 Principle of precaution as an adjunct in the decision-making process. & 4,9 & 0,4 & 4,6 & 0,8 & 4,4 & 0,5 & 4,3 & 1,0 \\
\hline 12. Role of health professionals & 4,5 & 0,7 & 4,3 & 1,3 & 4,4 & 1,0 & 4,0 & 1,6 \\
\hline 12.1 Information. & 4,7 & 0,5 & 4,6 & 1,1 & 4,7 & 0,8 & 4,1 & 1,6 \\
\hline 12.2 Counseling. & 4,6 & 0,5 & 4,4 & 1,1 & 4,4 & 1,0 & 4,0 & 1,5 \\
\hline 12.3 Monitoring. & 4,3 & 1,1 & 3,9 & 1,7 & 4,1 & 1,2 & 3,9 & 1,6 \\
\hline
\end{tabular}

values in bold correspond to averages and standard deviations of each theme.

$\mathrm{x}=$ average

$\mathrm{s}=\mathrm{standard}$ deviation

agreement (1-strongly disagree, 2-disagree, 3- neither disagree nor disagree, 4-agree, 5-strongly agree)

importance (1-unimportant, 2- little important, 3- neither little important nor unimportant, 4-important, 5-very important).

\section{Interviews}

In the interviews, there were questions that sought to achieve a variety of impressions and perceptions that the various individuals have in relation to the training module on TF. These perceptions were reorganized into secondary groups (Table 2), with transcription of some of the respondents' comments (in the sections below). In general, health professionals have made an important contribution in all aspects.

Table 2: Groups of answers given by nutritionists and physicians who were interviewed.

\begin{tabular}{|c|c|c|c|}
\hline Main Group & Secondary Groups & Nutritionists & Physicians \\
\hline \multirow{6}{*}{ 1. Contents } & The module is very comprehensive. & $\mathrm{x}$ & $\mathrm{x}$ \\
\hline & Some contents are more important than others. & $\mathrm{x}$ & $\mathrm{x}$ \\
\hline & Being careful about the relevance of each content. & $\mathrm{x}$ & $\mathrm{x}$ \\
\hline & Being careful about the duration of each module. & $\mathrm{x}$ & $\mathrm{x}$ \\
\hline & Being careful about the module operationalization. & $\mathrm{x}$ & * \\
\hline & $\begin{array}{l}\text { Need to set differences concerning the focus on the topics for each area - nutrition and } \\
\text { medicine. }\end{array}$ & $\mathrm{x}$ & $\mathrm{x}$ \\
\hline \multirow{5}{*}{ 2. Structure } & It is feasible to teach the module with several subtopics. & $\mathrm{x}$ & $\mathrm{x}$ \\
\hline & It depends on who and whom you work with to conceive the module. & $\mathrm{x}$ & $*$ \\
\hline & It depends on the type of information that is passed on. & * & $\mathrm{x}$ \\
\hline & Receptivity that may exist. & * & $\mathrm{x}$ \\
\hline & Insistence on this type of training. & * & $\mathrm{x}$ \\
\hline \multirow{4}{*}{ 3. Emerging Topics } & Although the program is strict, they agree that there must be changes. & $\mathrm{x}$ & $\mathrm{x}$ \\
\hline & Although the curriculum is rigid, there are gradual changes. & $\mathrm{x}$ & $\mathrm{x}$ \\
\hline & It is not included. & * & $\mathrm{x}$ \\
\hline & It is included in the degree whenever there is demand for it. & $*$ & $\mathrm{x}$ \\
\hline \multirow{4}{*}{$\begin{array}{l}\text { 4. Inclusion in the degree } \\
\text { plan }\end{array}$} & $\begin{array}{l}\text { In nuclear subjects: public health, nutrition, food technology and innovation, human } \\
\text { nutrition. }\end{array}$ & $\mathrm{x}$ & $*$ \\
\hline & In optional subjects. & $\mathrm{x}$ & $\mathrm{x}$ \\
\hline & In other training activities during the degree (lecture, workshop). & * & $\mathrm{x}$ \\
\hline & At the end of the degree. & $\mathrm{x}$ & * \\
\hline
\end{tabular}




\begin{tabular}{|c|c|c|c|}
\hline \multirow{8}{*}{ 5. Difficulties } & Lack of contents and materials for the module. & $\mathrm{x}$ & $*$ \\
\hline & Lack of knowledge of the methodology (multidisciplinary and STS). & $\mathrm{x}$ & * \\
\hline & Doubts about in which part of the curriculum it can be integrated. & $\mathrm{x}$ & * \\
\hline & The current teaching format may impair it. & $\mathrm{x}$ & $*$ \\
\hline & Lack of professors with the necessary competence. & $\mathrm{x}$ & $\mathrm{x}$ \\
\hline & Little time for many contents. & $\mathrm{x}$ & $\mathrm{x}$ \\
\hline & Having interested students. & $\mathrm{x}$ & $\mathrm{x}$ \\
\hline & Genetics: genetic construction, methods and processes. & $\mathrm{x}$ & $\mathrm{x}$ \\
\hline \multirow{4}{*}{ 6. $\mathrm{TF}$ framework areas } & Ethics and deontology. & $\mathrm{x}$ & $\mathrm{x}$ \\
\hline & Food toxicology. & $\mathrm{x}$ & * \\
\hline & Food technology. & $\mathrm{x}$ & * \\
\hline & Human nutrition. & $\mathrm{x}$ & * \\
\hline \multirow{7}{*}{ 7. Skills acquired } & Advising. & $\mathrm{x}$ & $\mathrm{x}$ \\
\hline & Informing. & $\mathrm{x}$ & $\mathrm{x}$ \\
\hline & Monitoring. & $\mathrm{x}$ & $\mathrm{x}$ \\
\hline & Developing critical analysis. & $\mathrm{x}$ & * \\
\hline & Achieving a better understanding of the subject. & $\mathrm{x}$ & $\mathrm{x}$ \\
\hline & Arousing the interest. & $\mathrm{x}$ & $\mathrm{x}$ \\
\hline & Forming an opinion. & $x$ & $x$ \\
\hline
\end{tabular}

$x$ corresponds to a response attributed by health professionals

*corresponds to the absence of response by health professionals.

\section{Group I - Contents}

With regard to content, what would you change, add or remove?

For the interviewees, the module's contents are well structured comprehensive, well explained and arranged by topics. On the other hand, based on the destination degree of the training offer, they consider some more important topics and other less important ones. They raise concerns about the relevance of each content because, being health professionals, they already consider having some knowledge foundations in specific areas. They also express concerns about the training's duration, which may be short and, finally, about the module's operationalization, since moments of discussion during the learning process would be necessary.

\section{Group 2 - Structure}

Do you think it is feasible to manage the module with multiple topics?

In relation to the module structure, which is multidisciplinary and focused on the STS approach, health professionals agree that it is feasible and expected, fundamental, desirable and essential, as the new challenges in the food field require more sustainable production. On the other hand, TF is on the market and tend to increase. A structure that depends on trainers and targets students is pointed out, so as to pass on the information and increase receptivity to the topic, the attendance of this kind of training at the academic level being important.

\section{Group 3 - Emerging Topics}

Does the degree structure follow the emerging topics?

The answers related to this group demonstrated the interest of curricular units' coordinators in keeping updated contents, depending on each professor and curricular unit that is taught, and fulfilling requirements stipulated by accrediting entities.

\section{Group 4 - Inclusion in the Degree Plan}

If it were to include the module of TF training in the curricular plans of the degrees in Medicine and Nutrition Sciences, in which curricular unit (s) would it be feasible?

They consider it important to include the module in the health portion. There are, however, differences in the approach between the Nutrition Sciences degree and the Medical degree. In Nutrition Sciences, it is stated that it can be taught as a nuclear or optional subject. In Medicine, since there is no nutrition subject, they refer to it as continuing training.

\section{Group 5 - Difficulties}

Which difficulties do you foresee with the module introduction?

The interviewees report lack of materials / information on $\mathrm{TF}$, lack of skills and difficulties in the multidisciplinary approach involving the module. There are doubts about the curricular units where the module can be integrated. There are also concerns about the receptivity of students and of health professionals and 
teachers, who are accustomed to a traditional teaching format and are resistant to changes in the structure of existing curricular units. They also anticipate difficulties in attracting interest.

\section{Group 6 - Transgenic Food Framework}

Is there any topic related to TF in the curricular plans of Medicine and Nutrition Sciences degrees?

Professionals report that there is not a single curricular unit that addresses TF; however, this topic may have been mentioned in genetics, either in the food context or in the human context. They consider that topics related to TF may also have been addressed in ethics, toxicology, food technology, community nutrition and public health. In the Medical degree, there is no curricular unit concerning nutrition and only contents related to risk factors of diseases are approached. There is a general absence of issues related to food quality and / or production.

\section{Group 7 - Skills Acquired}

What are the skills and competences to be acquired / developed with training?

Those interested, after training in $\mathrm{TF}$, should have the competence to impartially inform and advise users on TF. If patients consume TF, monitoring is important for studies on the impact of TF on health. They also point out that individuals who have been trained should be able to filter and synthesize information and be able to give a reasoned opinion, this critical analysis being a major challenge. However, only those interested can acquire more knowledge.

\section{Discussion}

Studies with a multidisciplinary approach and / or CTS are in the literature, especially in the health and food areas, and so they report positive results. However, there is no similar work in the literature as proposed in this investigation, allowing only comparisons by analogy.

\section{Feasibility of Teaching a Module with Multiple Subtopics}

The results of this work are similar with the findings of Alonge et al. [18], where feasibility in teaching a module with several subtopics is stated, that is, with transfer of knowledge from several perspectives. The work of Alonge et al. [18] was conducted in the USA in the format of a module for postgraduate students, using multiple approaches concerning "implementing research and practice in public health." The potential of this method is the ability to demonstrate the diffusion and transfer of knowledge from various perspectives. This teaching approach can potentially influence the method of teaching at the postgraduate level in health professions, where various subjects intersect.

\section{Difficulties in Applying the Module}

It was possible to detect fears in the receptivity of teachers who are possibly used to the traditional format. Similar opinions were presented in the studies of Gehlert et al. [19], Reme et al. [20], Daniel Stokols [21]. Other difficulties reported in this research come from getting interested students. Studies by Abubakari [22], Kartens and O'Connor [23], Gero [24], corroborate these findings. It is corroborated by Daniel Stokols [21], that overcoming these challenges would require strategic training and experience, along with encouraging the development of interpersonal skills. Therefore, in general managing a module for multiple themes depends on who and whom one works with.

\section{Skills to be Developed}

Both Nutritionists and Physicians point out advising, informing, monitoring, achieving a better understanding, arousing interest and forming opinions, as skills to be developed and acquired with this training. Studies by Lambert and Monnier-Barbarino [25], corroborate these findings. Through the formatting of a teaching module on reproductive health issues applied to undergraduate and graduate students, in which a pedagogical approach divided into three-stages (unidisciplinary, multidisciplinary and multi/ transdisciplinary) was utilized. The results achieved by each student were based on their ability to translate disciplinary knowledge, establish open dialogue, cross disciplinary barriers, separate themselves from their initial opinion, and develop curiosity about the perspectives and concerns of others [26].

\section{Health Professionals and the Module's Insertion in The Degree Plan}

The inclusion of the TF module in the Nutrition Sciences degree plan was more indicated in nuclear and / or elective subjects, such as: genetics, ethics, food toxicology, food technology and human nutrition. For the degree in Medicine, the prevalence was in optional subjects and / or activities at the end of the course. Possibly this difference comes due to the nature of the courses, as nutrition science is more related to food issues and medicine congruent with health. On the other hand, some studies point out and, therefore, corroborate, the importance of physicians knowing more about nutrition, given the constant need for them to approach this topic in patient care [26]. In view of this, there appears to be a growing demand for inclusion of emerging issues in the curricula [27], and the need to improve the nutritional education of health professionals [28].

These demands come from changing views on health and disease. There are an increasing number of studies about food production, nutrition, health and interrelations in the context of climate change, increasing populations and urbanization [29]; such as: studies in the field of public health, since there are countries that face food shortages, water, as well as socio-demographic and diet-related changes [30,31]; as well as studies on transgenic foods, which involve food supply issues [32]. In response, higher education is increasingly being asked to train students who are able to deal with emerging and complex issues [33], such as the TF topic. Complex issues are often shrouded in scientific uncertainties 
and concerns and therefore generate divergences and require a well-rounded approach that is simultaneously ethical and social, economic and even political [5]. Therefore, I conjecture that the discussion of emerging issues should be managed in a formation that incorporates all these conflicting and ambiguous aspects, in which the TF are undoubtedly inserted. We hope that the training through this module can support the understanding of TF and significantly improve patient care.

\section{Conclusion}

With unanimity, the individuals involved in this study agree and consider the themes presented in the module structure to be important, although there is a difference between the courses of nutrition science and medicine regarding the way in which training is offered and in some content. They point there are difficulties in implementing a module in this format, however, will not be impossible. They positively believe that the module will contribute to students' proactive skill development. In view of this, our research corroborated the findings that the training proposed for a medical and nutritionist audience will provide a comprehensive understanding of the complexity of the TF topic.

\section{References}

1. Pellegrino E, Bedini S, Nuti M, Ercoli L (2018) Impact of genetically engineered maize on agronomic, environmental and toxicological traits: a meta-analysis of 21 years of field data. Sci Reports 8(3131): 1-12.

2. Maghari BM, Ardekani AM (2011) Genetically modified foods and social concerns. Avicenna J Med Biotechn 3(3): 109-117.

3. Santis BD, Stockhofe N, Wal JM, Weesendorp E, Lalle JP, et al. (2017) Case studies on genetically modified organisms (GMOs): Potential risk scenarios and associated health indicators. Food Chem Toxicol 117: 3665.

4. Mansour N (2009) Science-Technology-Society (STS): A new paradigm in science education. Bulletin of Sci Techn Soc 29(4): 287-297.

5. Hilimire KHP, Gillon S, Mclaughlin BC, Dowd-uribe B, Monsen KL (2014) Food for thought: Developing curricula for sustainable food systems education programs. Agroecology and Sustainable Food Systems 38(6): 722-743.

6. NRC (2004) Methods and mechanisms for genetic manipulation of plants, and microorganisms. In: COUCIL, N. R. (ed.) Safety of Genetically Engineered Foods: Approaches to Assessing Unintended Health Effects. Washington (DC): National Academies Press.

7. Kramkowska M, Grzelak T, Czyzewska K (2013) Benefits and risks associated with genetically modified food products. Annals Agricult Environ Medicine 20(3): 413-419.

8. Brookes G, Barfoot P (2017) GM crops: global socio-economic and environmental impacts 1996- 2015, UK, PG Economics Ltd.

9. Domingo JL, Bordonaba JG (2011) A literature review on the safety assessment of genetically modified plants. Environment International 37(4): 734-742.

10. Dizon F, Costa S, Rock C, Harris A, Husk C, et al. (2016) Genetically modified (GM) foods and ethical eating. J Food Sci 81(2): 287-291.

11. Menozzi D, Kostov K, Sogari G, Arpaia S, Moyankova D, et al. (2017) A stakeholder engagement approach for identifying future research directions in the evaluation of current and emerging applications of GMOs. Bio-based and Applied Economics 6(1): 57-79.
12. Sanchez MA, Parrott WA (2017) Characterization of scientific studies usually cited as evidence of adverse effects of GM food/feed. Plant Biotechn J 15(10): 1227-1234.

13. Antoniou M, Robinson C, Fagan J (2012) GMO Myths and Truths, Earthopensource.

14. Nordgard L, Bohn T, Gillund F, Gronsberg IM, Iversen M, et al. (2015) Uncertainty in the knowledge base of GMOs. Biosafety, C. F. (ed.) Uncertainty and knowledge gaps related to environmental risk assessment of GMOs. Norway.

15. Rijssen FWJV, Eloff JN, Morris EJ (2015) The precautionary principle: Making managerial decisions on GMOs is difficult. South African J Sci 11(3-4): $1-10$

16. Bardin L (2009) Content Analysis, Lisbon (Análise de Conteúdo, Lisboa), LDA.

17. Hill MM, Hill A (2000) Research by questionnaire, Lisbon (Investigação por questionário, Lisboa).

18. Alonge O, Frattaroli S, Davey-rothwell M, Baral S (2016) A Transdisciplinary approach for teaching implementation research and practice in public health. Pedagogy Health Promot 2(2): 127-136.

19. Gehlert S, Murray A, Sohmer D, Mcclintock M, Conzen S, et al. (2010) The importance of transdisciplinary collaborations for understanding and resolving health disparities. Social Work in Public Health 25(3-4): 408-422.

20. Reme SE, Caban-martinez AJ, Arlinghaus A, Gray G (2015) From the schools and programs of public health. Public Health Reports 130: 553558.

21. Stokols D (2006) Toward a science of transdisciplinary action research. American J Community Psychol 38(1-2): 63-77.

22. Abubakari MR (2018) Towards an interdisciplinary approach to food accessibility research. Global J Human-Social Sc H Interdiscip18(1): 9-20.

23. Karsten HD, Connor REO (2002) Lessons learned from teaching an interdisciplinary undergraduate course on sustainable agriculture science and policy. J Nat Resour Life Sci Educ 31(1): 111-116.

24. Gero A (2017) Students' attitudes towards interdisciplinary education: a course on interdisciplinary aspects of science and engineering education. European J Engineering Educ 42(3): 260-270.

25. Lambert RD, Monnier-barbarino P (2005) Transdisciplinary training in reproductive health through online multidisciplinary problem-solving: A proof of concept. Eur J Obstet Gynecol Reprod Biol 123(1): 82-86.

26. Ball L, Crowley J, Laur C, Rajput-ray M, Gillam S, et al. (2014) Nutrition in medical education: reflections from an initiative at the University of Cambridge. J Multidiscip Healthcare 7: 209-215.

27. Irby DM, Wilkerson L (2003) Educational innovations in academic medicine and environmental trends. J General Internal Medicine 18(5): 370-376.

28. Krisetherton PM, Akabas SR, Bales CW, Bistrian B, Braun L, et al. (2014) The need to advance nutrition education in the training of health care professionals and recommended research to evaluate implementation and effectiveness. Am J Clin Nutr 99(5 Suppl): 1153S-1166S.

29. Garnett T (2013) Conference on 'Future food and health' Symposium I: Sustainability and food security. Proceedings of the Nutrition Society 72 : 29-39.

30. Foran T, Butler JRA, Williams LJ, Wanjura WJ, Hall A, et al. (2014) Taking complexity in food systems seriously: An interdisciplinary analysis. World Development 61: 85-101.

31. Horton P, Banwart SA, Brockington D, Brown GW, Bruce R, et al. (2017) An agenda for integrated system-wide interdisciplinary agri-food research. Food Security 9(2): 195-210. 
32. Verma SR (2013) Genetically modified plants: public and scientific perceptions. Hindawi Pub Corp pp. 1-11.

33. Choi BCK, Pak AWP (2008) Multidisciplinarity, interdisciplinarity, and transdisciplinarity in health research, services, education and policy: 3 .

ISSN: 2574-1241

DOI: $10.26717 /$ BJSTR.2021.34.005523

Isabella R F Vieira. Biomed J Sci \& Tech Res

(c) (P) This work is licensed under Creative Commons Attribution 4.0 License

Submission Link: https://biomedres.us/submit-manuscript.php
Discipline, inter-discipline distance, and selection of discipline. Clinical Investig Med 31(1): E41-E48.

$\begin{array}{ll}\text { BIOMEDICAL } & \text { Assets of Publishing with us } \\ \text { RESEARCHES } & \text { - Global archiving of articles } \\ \text { - Immediate, unrestricted online access } \\ \text { - Rigorous Peer Review Process } \\ \text { - Anttps://biomedres.us/ }\end{array}$

